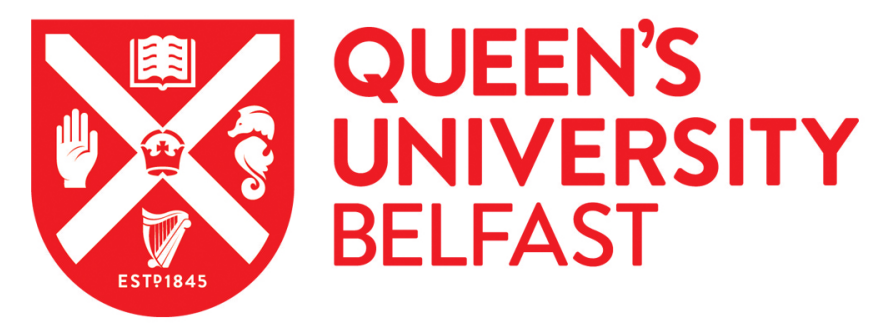

\title{
Testing Preference Formation in Learning Design Contingent Valuation Using Advance Information and Repetitive Treatments
}

Aravena, C., Hutchinson, W. G., Carlsson , F., \& Matthews , D. I. (2018). Testing Preference Formation in Learning Design Contingent Valuation Using Advance Information and Repetitive Treatments. Land Economics, 94(2), 284-301. https://doi.org/10.3368/le.94.2.284

Published in:

Land Economics

Document Version:

Peer reviewed version

Queen's University Belfast - Research Portal:

Link to publication record in Queen's University Belfast Research Portal

Publisher rights

Copyright 2017 by the Board of Regents of the University of Wisconsin System.

This is an accepted manuscript published under a Creative Commons Attribution-NonCommercial-NoDerivs License

(https://creativecommons.org/licenses/by-nc-nd/4.0/), whicjavascript:void(0); which permits distribution and reproduction for non-commercial purposes, provided the author and source are cited.

\section{General rights}

Copyright for the publications made accessible via the Queen's University Belfast Research Portal is retained by the author(s) and / or other copyright owners and it is a condition of accessing these publications that users recognise and abide by the legal requirements associated with these rights.

Take down policy

The Research Portal is Queen's institutional repository that provides access to Queen's research output. Every effort has been made to ensure that content in the Research Portal does not infringe any person's rights, or applicable UK laws. If you discover content in the Research Portal that you believe breaches copyright or violates any law, please contact openaccess@qub.ac.uk. 


\title{
Testing preference formation in learning design contingent valuation (LDCV) using advanced information and repetitive treatments
}

\author{
Dr. Claudia Aravena \\ School of Social Sciences \\ School of Energy, Geoscience, Infrastructure and Society \\ Heriot Watt University \\ Edinburgh, EH14 4AS, UK. \\ Ph. +44 (0) 1314513551
}

Gibson Institute for Land, Food and Environment Queen's University Belfast. Belfast. BT9 7BL, UK. E-mail:c.aravena@hw.ac.uk.

\section{Professor W. George Hutchinson}

Gibson Institute for Land, Food and Environment

Institute for Global Food Security and UKCRC Centre of Excellence for Public Health NI

Queen's University Belfast, Medical Biology Centre 97 Lisburn Road, Belfast. BT9 7BL, UK.

E-mail: g.hutchinson@qub.ac.uk.

Ph. +44 (0)2890972321

\section{Professor Fredrik Carlsson}

Department of Economics University of Gothenburg

Box 640, SE-40530 Gothenburg, Sweden

E-mail: Fredrik.Carlsson@economics.gu.se.

Ph. +46 (0)31-786 4174

\section{Dr. David I. Matthews}

Agri-Food and Biosciences Institute (AFBI)

Newforge Lane, Belfast. BT9 5PX, UK.

E-mail: Dave.Matthews@afbini.gov.uk.

Ph. +44 (0)2890255627 


\title{
Testing preference formation in learning design contingent valuation (LDCV) using advanced information and repetitive treatments
}

\begin{abstract}
Policymakers have largely replaced Single Bounded Discrete Choice (SBDC) valuation by the more statistically efficient repetitive methods; Double Bounded Discrete Choice (DBDC) and Discrete Choice Experiments (DCE). Repetitive valuation permits classification into rational and irrational preferences: (i) a-priori well-formed; (ii) consistent non-arbitrary values "discovered" through repetition and experience; (Plott 1996; List 2003) (iii) consistent but arbitrary values as "shaped" by preceding bid level (Tufano 2010; Ariely et al. 2003) and (iv) inconsistent and arbitrary values. Policy valuations should demonstrate behaviorally rational preferences. We outline novel methods for testing this in DBDC applied to renewable energy premiums in Chile.
\end{abstract}

Key words: Contingent valuation; double bounded discrete choice; repetitive learning; advanced information learning; bid dependency; theories of preference formation; renewable energy. 


\section{INTRODUCTION TO LEARNING DESIGNS AND THEORIES OF PREFERENCE FORMATION}

The Contingent Valuation Method (CVM) has been the Stated Preference methodology most used to elicit values of non-market goods in different fields. ${ }^{1}$ A major issue of discussion in the application of this method has been the selection of the elicitation format. The NOAA panel (Arrow et al. 1993) and Carson et al. 2003 recommend the use of a Single Bounded (SB) referendum format due to the claimed potential incentive compatibility property that Gibbard 1973 and Satterthwaite 1975 had established for binding referenda where real payments are in place. Despite these claims, evidence of convergence between SB contingent valuation results and real referendum mechanisms in economic experiments is decidedly mixed even when these experiments involve common market goods and straightforward market institutions (Burton et al. 2009; Cummings et al. 1997; Loomis et al. 1997; Taylor et al. 2001). Trends in Stated Preference research over the last two decades have seen the SB format largely side-lined for several reasons. Firstly, almost all recent developments in Stated Preferences have been towards the use of repetitive valuation methods, which provide greatly improved statistical efficiency and analytical insight such as multiple bounded CVM (Hanemann et al. 1991) and Discrete Choice Experiments (Louviere et al. 2000). Secondly these repetitive mechanisms are more consistent with important trends in behavioural economics that are concerned with the fundamental nature of human preference formation, where the Discovered Preference Hypothesis (DPH) by Plott 1996 argues that stable and theoretically consistent preferences are not pre-existent but the product of experience gained through practice and repetition. Plott argues that functioning markets provide such repetition and learning, whereby individuals can discover the rules of the market, a process called "institutional learning" (by Braga and Stamer 2005), and discover their personal preferences through a process these authors call 
"value learning”. In a seminal paper on this subject Plott and Zeiler 2005 examine whether internal consistency between values of Willingness to Pay (WTP) and values of Willingness to Accept (WTA) exists in initial valuations or whether such consistency is discovered or learned in repeat valuations. In a series of economic experiments they find that initial values are not consistent, but subsequent values are. Similarly, they find that the well-known anomaly known as the endowment effect is present in the initial elicitation, but not in the repeat elicitations. This theory of consistent preference formation through experience (after List 2003) or learning (after Plott 1996) is opposed to the alternative a-priori well-formed preference hypothesis which holds that existing preferences are consistent and can be most accurately elicited by single shot elicitation methods such as Single Bounded Dichotomous Choice (SBDC). In the experimental economics literature it has been argued that learning processes of this type attenuate major theoretical preference anomalies such as the above-mentioned WTP/WTA difference and the endowment effect (e.g. List 2002, 2003, 2004; Plott and Zeiler 2005).

Bateman et al. 2008 was the first paper to apply these ideas to Stated Preference and claimed (on pp128-129) that "The first response SB format precludes either institutional or value learning and is in direct conflict with the DPH which would suggest that it is the last response in a series of valuations which should be attended to rather than the first". This idea of preference learning during repeated choices has also been taken up by researchers using Discrete Choice Experiments (DCE) who have also observed that estimates of both preferences and variance obtained from the initial choice are often out of line with those obtained from subsequent choices (Carlsson et al. 2012; Hess et al. 2012; Czajkowski et al. 2014 Campbell et al. 2015). This discussion in DCEs is further supported by the earlier classic literature in this discipline which describes in purely 
empirical observational terms learning and fatigue effects in sequential DCE valuations (Brazell and Louviere 1996; Bradley and Daly 1994).

The Double Bounded Dichotomous Choice (DBDC) approach in contingent valuation was introduced by Hanemann et al. 1991. It is an SBDC format with a follow-up discrete choice question. When a "yes" response is given to the SBDC question a higher bid level is offered; while a lower bid level is offered if there is a "no" response. This repetitive mechanism produces a more precise bounding of individuals' willingness to pay and provides more statistically efficient estimates of values (Hanemann et al. 1991; Alberini 1995). One of the major anomalies of DBDC refers to the internal inconsistency between the single bounded (SB) and the double bounded (DB) estimates derived from the same data set. This inconsistency relates to the considerably higher WTP estimates produced by the SBDC response to the first bid compared to the DB analysis, which is applied to the first and follow-up bids. The earliest papers on DBDC have demonstrated this difference (Hanemann et al. 1991; Cameron and Quiggin 1994; McFadden 1994) and the difference is referred to as stylized fact in an influential review paper by Carson and Groves 2007 and represents one of the main criticisms of the DBDC elicitation format (DeShazo 2002). ${ }^{2}$ However, Bateman et al. 2008 demonstrates that this inconsistency in SB and DB WTP is statistically significant when a single good is valued in isolation, but this inconsistency in value is shown to be attenuated in repetitive valuations of several goods.

Bateman et al. 2008 also introduced the concept of Coherent Arbitrariness (Ariely et al. 2003) into Stated Preference Valuation. Ariely et al. 2003 show that consistency is a necessary but not a sufficient condition for well-formed preferences. The theory of preference formation by Ariely et al. 2003; Loomes et al. 2003 and Tufano 2010, holds that preferences may be internally consistent 
but potentially context dependent as strongly influenced by an arbitrary anchor, which can be an initial or a preceding bid level in the sequence. This hypothesis is termed "Coherent Arbitrariness" by Ariely et al. 2006 and Maniadis et al. 2014 and as the "Shaping Hypothesis" by Tufano 2010 and Loomes et al. 2003. ${ }^{3}$

In this paper we return to the issue of consistency and bid dependency in DBDC surveys. Our starting point is that repetitive learning (Bateman et al. 2008) can potentially reduce bid dependency and observed internal inconsistency between SB and DB estimates. However, we are primarily interested in whether advanced information about the sequence of goods to be valued, the DB referendum mechanism and institution, and the DB decision rule can have a similar effect on behaviour as repetitive learning. In particular with repetitive valuation and disclosure of information in advance we test whether preferences are consistent with one of four theories of preference formation:

1. the initial valuations without advanced disclosure or repetitive processes conforms to conventional economic theory by demonstrating pre-existent well-formed preferences,

2. well-formed preferences are "discovered" through a process of "learning" which takes place during the repetitive valuation and /or advanced disclosure processes (Plott 1996; List 2003),

3. preferences are internally consistent but arbitrary as "shaped" by preceding bid level (Tufano 2010; Ariely et al. 2003),

4. or preferences are internally inconsistent and reveal order effects throughout the sequence of valuations even when advanced information is provided (Day et al. 2012). 
The rest of the paper is organized in the following way. In Section 2 we describe the design of the study. Section 3 describes the methodology and hypothesis to be tested. Section 4 presents the results and finally Section 5 concludes the paper.

\section{DESIGNS FOR ADVANCED INFORMATION AND REPETITIVE LEARNING IN DBDC}

\section{Study Design}

In this paper we attempt to create the information effects of a multiple repeat learning design (Bateman et al. 2008) by advanced information. We attempt to provide the information respondents acquire from repetition by informing them in advance about the DBDC institution, and the sequence of goods to be valued. In addition, we also provide information about the incentive compatible (IC) double referendum decision rules regarding the provision of the good. We test whether this approach is equally or more effective than repetitive learning in reducing internal inconsistency and first bid dependency in DBDC responses. In particular, we test whether it is capable of producing consistent and non-arbitrary values in both first good as well as repeat valuations thus abolishing the need for an initial training round. To this end, we use a split sample approach in which the sample is divided into three information treatments: (i) Treatment 1, respondents are uninformed about the sequence of goods to be valued, the DBDC institution and the incentive compatible decision rules for the double referendum; (ii) Treatment 2, respondents are informed in advance about the goods to be valued and the DBDC institution in terms of the sequence of two bids; and (iii) Treatment 3, respondents are informed in advance about the goods 
to be valued, the DBDC institution and the incentive compatible decision rules for the double referendum following the method used to investigate DBDC decision rules in an experiment by Carson et al. 2009. Given that in our three treatments two sequential valuations are presented to each group we generate a $3 \times 2$ design containing six different methods of conducting double bounded dichotomous choice contingent valuation. Four of these methods have not previously been studied. We test all six methods for the degree to which they achieve internal consistency, freedom from first bid dependency effects, and whether the efficiency of the estimates is improved by including the advanced information. Figure 1 summarizes the treatments and types of learning considered in this paper.

$>>>$ Figure 1

For notational purposes we denote $\overline{W T P}_{S B, k}^{i}$ as the single bounded mean willingness to pay for valuation $i$, where $i=1$ is the first valuation and $i=2$ is the second valuation and $k$ represents the advanced information treatment, where $k=1,2$ and 3 according to the level of information provided in each treatment (See Figure 1). Similarly, $\overline{W T P}_{D B, k}^{i}$ denotes the double bounded mean willingness to pay, and $\Delta \overline{W T P}_{k}^{i}=\overline{W T P}_{S B k}^{i}-\overline{W T P}_{D B k}^{i}$. Thus, $\Delta \overline{W T P}_{k}^{i}$ shows the difference between the single bounded and double bounded estimates for each of the six DBDC methods considered in Figure 1 as differentiated by information levels and position in the sequence as first or second valuation. ${ }^{4}$ In addition, we estimate an "anchoring" parameter, $\gamma_{k}^{i}$, for each case, representing the dependency of the responses to the second bid on the level of the first bid; see equations [3] and [4] in section 3.5. The value and statistical significance of these two estimates allows us to gage the anchoring and 
consistency present in the six DBDC datasets obtained for the six methods presented below. This also allows us to attribute a preference formation theory to each of these learning design methods in Figure 1.

The first case (Treatment $1-1^{\text {st }}$ valuation) in Figure 1 is the standard double-bounded format, with uninformed respondents and only one (double bounded) valuation task. The second case (Treatment $1-2^{\text {nd }}$ valuation) corresponds to the test in Bateman et al. 2008 with uninformed respondents but a repeat double bounded valuation of a second good. The four other cases are all new methods, the difference being the amount of information provided and with or without repeat valuations. What we wish to investigate is whether providing advanced information to respondents offers an alternative method for implementing learning design contingent valuation. As far as we know, none of our advanced information designs have previously been studied in field applications.

\section{Advanced Information to Respondents on the DBDC Institution and Goods Valued}

In general, DBDC surveys do not inform respondents about the way this mechanism works and it is stated that the follow-up question generates a surprise effect that could annoy respondents or cause indignation, guilt, strategic behaviours or free-riding. Considering this issue, Cooper et al. 2002 introduces descriptive information regarding the follow-up bid in order to diminish the surprise effect when individuals face the second question. Advanced information on the DBDC institution is a type of learning, which consists of informing respondents, before they perform the valuation tasks, about the number of bids that will be presented and the way the DBDC mechanism works. The provision of this information also facilitates institutional learning effects similar to the repetitive learning design. This is similar to the idea of advanced disclosure and visible choice sets 
introduced by Bateman et al. 2004. Existing literature deals only with the consistency effect of the advanced information. This paper is the first to our knowledge to study possible effects of such information on anchoring and bid dependency and on preference formation theories.

In order to test the effect of informing respondents in advance about the DBDC institution and the sequence of goods to be valued, we introduce Treatment 2 (Informed DBDC). This treatment uses exactly the same questionnaire used in Treatment 1 but it includes additional information. We inform respondents that they will vote in two referenda each involving two valuation questions. First, they will value renewable energy against a hydropower status quo alternative and then they will value renewable energy against a fossil-fuels status quo. ${ }^{5}$ However, the main objective is to explain the DBDC mechanism in a manner which seems reasonable and acceptable to respondents. The wording used for this was the following:

"Because the exact cost of the (renewable energy) projects is not known today, we will ask you to vote on two different costs for the project. These costs represent the range into which the actual cost should fall. In what follows, you will vote for or against each alternative. You are asked how you would vote if the good could be provided at one of the two costs. This is followed directly by a second vote on how you would vote if the good could be provided at the second of the two costs."

It is important to point out that respondents were not informed about the conditionality of the second bid. Thus, they did not know that the level of the second bid depends on their response to the first bid. This withholding of information is necessary to avoid a clear opportunity for strategic behavior in the DBDC mechanism. 


\section{Advanced Information to Respondents on the Incentive Compatible Double Referendum Decision Rules}

A decision rule in DBDC refers to the conditions that characterize the provision of the good under the double referendum mechanism. In the case of DBDC it refers to the explanation of how the responses to the two referenda will influence the final decision whether the good will be provided or not and at what cost (Carson et al. 2009).

In this context, two key rules should be explained: i) the percentage of votes required for the referendum to pass, and ii) in case the second vote fails, an explanation of whether the good is provided at the first price or not provided at all. These are crucial rules affecting the incentive compatibility and outcome of the double referendum method. By making decision rules clear to respondents, strategic behaviour in the double referendum may be avoided and in consequence, the WTP estimates based on the SB and DB information may become more internally consistent and exhibit less bid dependent anchoring.

To study the additional effect of advanced information about the incentive compatible decision rules we introduce Treatment 3 (Informed DBDC + IC Double Referendum Decision Rules). In addition to the information introduced in Treatment 2, this treatment incorporates an extra paragraph presenting an explicit explanation regarding the final outcome of the two votes and how this relates to the provision of the good. Decision rules are introduced immediately after the first valuation question for each good. Decision rules regarding the final vote cannot be introduced before the first valuation question because it would invalidate this response and present a clear incentive for strategic behaviour, allowing respondents to answer "no" to the first referendum and "yes" to the second one in order to secure the provision of the good at a lower cost. In our study it was clearly stated that in the second referendum if a majority of the participants would vote "yes" 
to the provision of the good, the project would go ahead, otherwise the outcome would be the initial status quo level. It was also clearly stated that the second vote would replace the decision of the first one, and if this second vote does not pass with a majority, the good would not be provided at all. On the other hand, if it passes, the good would be provided at the cost presented in the second vote. The wording used in this treatment was the following:

"Now imagine that the cost to you was $\$$ (the higher or lower second price) and the outcome of this second vote replaces that of the first vote, so that if a majority vote "Yes" in favour of this proposal the renewable energy projects are developed and if a majority vote "No" the Patagonian dams project will go ahead. We will not ask you to vote again at another cost on this proposal".

"Would you vote Yes or No?”

An effect on consistency by introducing explicit IC decision rules has been shown in an economic laboratory experiment by Carson et al. 2009. With real incentives in place, subjects were seen to provide highly biased responses when failure of the second referendum vote was described as resulting in the implementation of the outcome of the first referendum. It is quite possible that many respondents in field studies implicitly make this (quite realistic) default scenario. When this default is not ruled out in the instructions respondents may attempt to exploit this possibility by strategically voting Yes/No instead of a demand revealing Yes/Yes vote in an attempt to lower the cost of the good. In our case, we study the effect in the field of providing an explicit explanation of the outcome of the second vote in a DBDC mechanism for the first time. On the other hand, to our knowledge the effect of the IC decision rules on bid dependent anchoring has never been studied previously. 


\section{Details of the survey and the good}

Electricity demand in Chile is forecasted to increase by $7 \%$ per annum over the next 25 years (NEC report on electricity prices 2007). At the moment almost all energy is generated by a mix of thermoelectric sources and large hydropower developments, which are recognized to be ecologically damaging. We conducted a contingent valuation survey on the willingness to pay premium for environmentally friendly renewable energy sources (RES) including biomass, wind, and solar power. The survey was conducted by personal interviews in the metropolitan area of Santiago and Concepcion, the two largest cities in Chile. The respondent selected for interview within each household were those responsible for paying the electricity bill.

Households were chosen from a random selection of streets from all areas of the city following a two stage random sampling procedure, stratified by socio-economic status. The different versions of the questionnaires were distributed randomly across households. The questionnaire design was based on several focus group discussions and pilot studies conducted in both cities. On the basis of the findings of the pilot studies bid vectors were designed for each good, following the method used in Scarpa and Bateman 2000 and Hutchinson et al. 2001. The bid vectors extended from 200 Chilean Pesos (CLP) to 10,000 CLP ${ }^{6}$ and each consisted of six levels of which four were used as starting points and the initial bids were randomly allocated for each scenario valued. Data was collected from 1093 households. Of these, 90 were rejected from the sample due to non-response and protests, leaving 1003 responses available for analysis.

In our contingent valuation questionnaire two valuation tasks were presented sequentially to three groups: one group of uninformed respondents, and two groups with two different levels of advanced information following Figure 1. The good to be valued was the introduction of a mix of 
renewable energy sources to produce additional electricity requirements against two alternative sources explained below, which were presented sequentially in the same questionnaire. Before the valuation questions, individuals were presented with a scenario that included information about the Chilean energy market, the rising electricity demand and the need of introduction of new energy sources to increase the supply. The good to be valued and each of the status quo situations were then described. In the first case, the status quo alternative was the construction of large hydroelectricity dams in Chilean Patagonia, and in the second case the status quo alternative was the installation of thermoelectric power plants in Central Chile ${ }^{7}$. Individuals were asked to treat both scenarios independently following the exclusive list procedure, avoiding substitution and related sequencing effects (Carson and Groves 2007). In order to reduce the influence of hypothetical bias a cheap talk script was included (Cummings and Taylor 1999).

\section{III.ECONOMETRIC METHODS AND HYPOTHESES TESTS}

From the referendum data we estimate logit models for both the SB and DB contingent valuation responses to identify the effects of providing advanced information on the goods to be valued, the DBDC institution and IC decision rules, as well as the effect of repetitive learning on the differences between mean WTP from SB and DB estimates, the standard errors of the estimates and the estimated anchoring parameters. We investigate four issues: The first two concerns the internal consistency between the SB and DB data. The third is to what extent advanced information learning and repetitive learning improve the efficiency of SB and DB estimates. The fourth and final issue we look at is the effect of advanced information and repetitive learning on the anchoring 
parameters, representing the dependency of responses to the second bid on the value of the first bid.

\section{The effect of advanced information on internal consistency without repetitive learning}

In order to test the effect of advanced information without repetitive learning we look at the difference between $\overline{W T P}_{S B}$ and $\overline{W T P}_{D B}$ for the first valuation scenario for all three treatments. The difference is denoted as $\Delta \overline{W T P}_{k}^{i}$, where $i$ refers to the scenario valued and $k$ denotes the treatment. We test the hypothesis that the difference in estimates of mean WTP between SB and DB are zero for each of the three treatments $\left(\mathrm{H}_{0}: \Delta \overline{W T P}_{k}^{1}=0\right)$. Based on standard results in the literature we expect to reject the hypothesis of consistency in the control treatment $\left(\Delta \overline{W T P}_{1}^{1}\right)$ with uninformed respondents. For the second treatment $\left(\Delta \overline{W T P}_{2}^{1}\right)$ we test whether advanced information about the DBDC institution and the goods to be valued is sufficient to result in consistent responses. Finally, for the third treatment $\left(\Delta \overline{W T P}_{3}\right)$ we test whether the introduction of advanced information about the DBDC institution, the goods to be valued and the IC double referendum decision rules result in consistent responses. In order to test for empirical differences in mean WTP between SB and DB estimates, we use a bootstrap technique (Efron and Tibshirani 1993; Bateman et al. 2008). This technique has previously been used in CVM for estimating confidence intervals by Kling 1991 and Cooper 1994. It was later used by Giraud et al. 2001 and Cooper et al. 2002 to estimate differences in WTP for different goods. The reason for selection of this method is the non-independence of the values obtained for the two elicitation questions. The responses for the second referendum depend on the responses given to the first bid in the SB referendum and they come from the same 
individual, thus generating non-independent responses. ${ }^{8}$ Therefore, the covariance between these two values is not zero and the application of a conventional $t$-test would be inappropriate.

It is also of interest to look at the value differences in $\Delta \overline{W T P}_{k}^{1}$ between treatments, i.e. the treatment effects on the extent of inconsistency in responses between SB and DB. We will test the null hypothesis that treatments with additional information will result in a lower difference between SB and DB mean WTP, i.e. $\mathrm{H}_{0}: \Delta \overline{W T P}_{k}^{1}-\Delta \overline{W T P}_{k+1}^{1}>0$. Thus following Figure 1, we will compare the control treatment with Treatment 2 to investigate the effect of adding information about the DBDC institution and the goods valued $\left(\Delta \overline{W T P}_{1}^{1}-\Delta \overline{W T P}_{2}^{1}\right)$, and Treatment 2 with Treatment 3 to investigate the effect of adding further information about the double referendum decision rules ( $\left.\Delta \overline{W T P}_{2}^{1}-\Delta \overline{W T P}_{3}^{1}\right)$

\section{The effect of repetitive learning on internal consistency}

As demonstrated by Bateman et al. 2008 experience gained through repetition alone can generate internally consistent estimate for SB-DB values in contingent valuation. This repetitive valuation is included as initial and repeat valuations in our design. We expect the estimated $\Delta \overline{W T P}_{k}^{i}$ to be lower when respondents face a repeat valuation given that they have had the opportunity to learn about their values, the goods and the institution in the earlier valuation.

Repetitive learning in Treatment 1 with uninformed respondents $\left(\Delta \overline{W T P}_{1}^{2}\right)$ is similar to the test in Bateman et al. 2008 . 
For each treatment we test the null hypotheses that the SB-DB difference is zero; the null hypothesis for treatment $k$ and scenario $i$ is $\mathrm{H}_{0}: \Delta \overline{W T P}_{k}^{i}=0$. If for the first treatment we do not find support for the null hypothesis for the first valuation scenario but for the second, the finding of Bateman et al. 2008 that LDCV based on repetitive learning is necessary to attenuate the SB-DB value difference can be demonstrated. What we investigate here is to what extent repetitive learning is important in attenuating the inconsistency in all treatments, even in the treatments where respondents have been informed in advance about the sequence of goods to be valued, the institution and the IC double referendum decision rule.

Finally, we will also look at the differences in $\Delta \overline{W T P}_{k}^{2}$ between treatments, i.e. the treatment effects on the extent of inconsistency in responses between SB and DB for the second good valued. Similarly as for the first valuation scenario we compare the control treatment with Treatment 2 to investigate the effect of adding advanced information about the DBDC institution and the goods to be valued to a single repeat valuation $\left(\Delta \overline{W T P}_{1}^{2}\right.$ versus $\left.\Delta \overline{W T P}_{2}^{2}\right)$, and Treatment 2 with Treatment 3 to investigate the effect of adding information about the IC double referendum decision rules to a single repeat valuation $\left(\Delta \overline{W T P}_{2}^{2}\right.$ versus $\left.\Delta \overline{W T P}_{3}^{2}\right)$.

\section{The bootstrap procedure to test internal consistency}

As mentioned above, to test the hypothesis involving a comparison of $\overline{W T P}_{S B k}^{i}$ and $\overline{W T P}_{D B k}^{i}$ within a treatment, a non-parametric bootstrap technique (Efron and Tibshirani 1993) is used to obtain the distribution of differences, $\Delta \overline{W T P}_{k}^{i}$, and compute the standard errors of these differences $\operatorname{se}\left(\Delta \overline{W T P}_{k}^{i}\right)$ controlling for the sampling design where values are obtained for mean $W T P$ from the 
same sample of respondents. This method was originally outlined in this context by Bateman et al. 2008 and involves the generation of repeated sampling with replacement from the original sample of households (the primary sampling unit). This technique controls for the non-independence of values, takes into account the covariance between these samples and allows for non-normal distributions, which are common in non-market valuations.

Considering the estimate of difference in mean WTP for the sample, then for a single bootstrap sample $b$ drawn with replacements, the estimate from the $b^{\text {th }}$ sample will be $\Delta \overline{W T P}_{k}^{i}(b)$. The estimated standard error se $\left(\Delta \overline{W T P}_{S B-D B, k}^{i}\right)$ using $B$ bootstrap samples, where all samples are the same size as the original sample $(N)$, is given by the standard deviation of all $B$ bootstrap estimates as follows:

$$
\begin{aligned}
& \operatorname{var}\left(\Delta \overline{W T P}_{k}^{i}\right)=\frac{\sum_{b=1}^{B}\left(\Delta \overline{W T P}_{k}^{i}(b)-\Delta \overline{W T P}_{k}^{i}\right)^{2}}{B-1} \\
& \operatorname{se}\left(\Delta \overline{W T P}_{k}^{i}\right)=\sqrt{\operatorname{var}\left(\Delta \overline{W T P}_{k D B}^{i}\right)}
\end{aligned}
$$

An empirical distribution of $\Delta \overline{W T P}_{k}^{i}$ is created using 10,000 replications of $\overline{W T P}_{S B}-\overline{W T P}_{D B}$. We use the percentile method to calculate confidence intervals and analyze the differences in the mean WTP. The results of the confidence intervals and the respective $\Delta \overline{W T P}_{k}^{i}$ are determined using the empirical distributions of differences. The hypothesis is accepted if the $90 \%$ confidence interval is composed of both negative and positive values and can therefore be shown to contain a value of zero difference. The hypothesis is rejected if the $90 \%$ confidence interval is composed of 
strictly positive or strictly negative values, meaning that the difference between mean SB-DB estimates $\left(\Delta \overline{W T P}_{k}^{i}\right)$ is strictly positive or strictly negative. The percentile confidence intervals $\left[b_{p 0.05}, b_{p 0.95}\right]$ for a series of $B$ bootstrap samples with estimates $b_{1}, b_{2}, \ldots, b_{\mathrm{B}}$ are obtained from the bootstrap distribution of differences using the $5^{\text {th }}$ and $95^{\text {th }}$ percentiles from the ordered set of bootstrap values $\left(b_{1}, b_{\mathrm{B}}\right)$ as bounds for the $90 \%$ confidence intervals of the difference.

\section{Effects of advanced information and repetitive learning on efficiency of WTP estimates}

Introduction of Advanced Information to respondents of the DBDC Institution and goods to be valued in Treatment 2 and IC Double Referendum Decision Rules in Treatment 3 may have an effect on both the mean and standard errors of SB and DB estimated welfare measures separately. This hypothesis establishes whether Treatments 2 and 3 in Figure 1 provide more accurate and efficient welfare estimates defined as a reduction in the standard errors as we move from the uninformed first valuation control treatment (Treatment 1) to the treatments including advanced information (Treatment 2 and 3). To this end, we calculate the coefficient of variation for each $\overline{W T P}$ estimate in all the treatments and goods valued and compare these results.

\section{Testing the bid dependent anchoring effect for each good and treatment.}

We want to identify to what extent the value of the first bid offered in DBDC will influence the acceptance of the second bid for each good. In particular, we wish to investigate whether the 
influence of anchoring/bid dependency varies between the three treatments with different levels of informed choices.

To test the dependencies of the second bid willingness to pay on the first bid amount we apply the anchoring model of Herriges and Shogren 1996. This model tests for the occurrence and magnitude of the anchoring effect and estimates the extent to which the acceptance level of the second bid is affected by the amount of the first bid value offered to the respondent for the same good. The method introduces an anchoring parameter, $\gamma$, into the logit model which adjusts the second bid WTP to become a weighted average of prior WTP and the first bid level offered. The anchored Willingness to Pay response to the second bid $\left(W T P_{r}\right)$ is:

$$
W T P_{r}=(1-\gamma) W T P_{0}+\gamma b_{1}
$$

where $W T P_{0}$ is the prior WTP and $b_{1}$ is the initial bid offered to the respondent. The effective revised bid level of the second bid, $b_{2 r}$, then becomes:

$$
b_{2 r}=\frac{\left(b_{2}-\gamma b_{1}\right)}{(1-\gamma)}
$$

The size and significance of the anchoring parameter is a test to the extent to which the second bid response is anchored on the initial bid level. If preferences are coherent, but in an arbitrary fashion, bid dependent anchoring is expected to be significant throughout the two valuation tasks. On the other hand, for discovered preferences, anchoring should be reduced over the sequence of valuation tasks. 


\section{RESULTS}

To begin with, we estimate logit models for single and double bounded responses for the three treatments. Parsimonious models are used throughout because of the complexity of the designs and testing procedures used. The model estimates are presented in Tables A1 and A2 in Appendix A.

As expected, the parameter estimates on the bids are negative and significant in all cases and are of similar magnitude. Using the estimated parameters we calculate the mean WTP $(\overline{W T P})$ for the first valuation (WTP for RES over hydropower) and second valuation scenario (WTP for RES over thermoelectric) for each treatment. Results are summarized in Table 1. WTP is reported in Chilean Pesos. We used the software NLogit for estimation.

>> Table 1

Results in Table 1 support the findings of Hanemann et al. 1991 and Alberini 1995 about the efficiency improvements of DBDC; i.e. that DB estimates are generally more efficient welfare measures than SB, as observed by the significantly lower standard errors in all cases. In the table we also report the differences between mean WTP in SB and DB $\left(\Delta \overline{W T P}_{k}^{i}\right)$ for the six DBDC methods considered in Figure 1. We can observe that differences decrease as we move from the first valuation in the uninformed treatment to the second valuation in the same treatment and even more when advanced information on the DBDC institution, the goods and IC decision rules are provided to respondents (Treatments 2 and 3). In order to test the null hypothesis that $\Delta \overline{W T P}_{k}^{i}$ is zero we employ the bootstrap procedure as described above. Employing the percentile method we construct a $90 \%$ empirical confidence interval. Results are reported in Table 2 . We use the $90 \%$ 
confidence interval because although the overall sample is over 1000, the nature of a three treatment design means we have just over 300 respondents in the treatments.

$\gg>\quad$ Table 2

Before we proceed with the results in detail it is necessary to comment on the results for Treatment 1 - the Uninformed Treatment. The difference in mean WTP between the SB and DB format is very large for the first good valued in that treatment. Still we cannot reject the null hypothesis of consistency in willingness to pay as is shown in Table 2 . This is a consequence of the high standard error in mean WTP for the SB response (see Table 1). We believe that this is another manifestation of the problem with the first valuation in a SB question format. This result is also in line with the uncommented findings on the initial SB standard error in Bateman et al. 2008. We will therefore proceed with testing the hypotheses for advanced information and repetitive learning, since we believe this result for $\Delta \overline{W T P}_{1}^{1}$ is driven by the large standard error in the one-shot single bounded question.

\section{The results of advanced information learning on internal consistency without repetitive}

\section{learning}

The effects of advanced information learning without repetitive learning are revealed by the hypotheses tests for equality in SB and DB WTP in Table 2. The null hypothesis of consistency between $\overline{W T P}_{S B k}^{i}$ and $\overline{W T P}_{D B k}^{i}$ cannot be rejected for the initial valuation in the two treatments with advanced information (Treatments 2 and 3). This is an indication that advanced information about the DBDC institution and goods valued affects the understanding of the institution and 
produces a high degree of internal consistency even in first valuations. This highlights two new methods for conducting Learning Design Contingent Valuation using Advanced Information and adds considerably to the insights in Bateman et al. 2008. At the same time, given the high variance presented in the SB estimate, we cannot reject the null hypothesis of consistency for the uninformed control treatment even though the difference in WTP estimates $\left(\Delta \overline{W T P}_{1}^{i}\right)$ is substantial. In addition, in the uninformed control treatment the SB-DB difference is significantly different from zero in the second valuation. Our findings in this Table 1 clearly suggest that in many ways advanced information has stronger effects than repetitive learning in producing internally consistent estimates.

Table 2 shows increasing consistency in first valuations as more advanced information is given to respondents. In Table 3 we test whether each of the two additional information treatments make a statistically significant improvement in SBDB consistency. This is what we call the Treatment Effect.

> Table 3

Table 3 shows that both additional information treatments make a significant improvement in reducing the SBDB value differences. Introducing advanced information learning about the DBDC institution and the good valued reduces the differences (between Treatment 1 and 2) by almost $63 \%$ and the addition of IC double referenda decision rules reduces this by a further $31 \%$ (between Treatment 2 and 3). Thus, advanced information to respondents offers an alternative method to repetition for implementing learning design contingent valuation. 


\section{The results of repetitive learning on internal consistency}

Based on the findings in Bateman et al. 2008 we expect that performing repeated valuation questions would result in responses that are internally consistent once respondents have gained valuation experience. If we begin with the control treatment method (1), we can observe in Table

2 that $\Delta \overline{W T P}_{k}^{i}$ is substantially lower in the second valuation scenario. However, in this case $\Delta \overline{W T P}_{1}^{2}$ is still significantly different from zero. Thus, contrary to Bateman et al. 2008 a single repeat DB valuation of a second good was not sufficient to obtain SB-DB consistency. What about the two other treatments? For both treatments with advanced information, the second valuation differences' $\Delta \overline{W T P}_{k}^{2}$ are smaller compared to the first valuation differences' $\Delta \overline{W T P}_{k}^{1}$, and we cannot reject the null hypothesis of no differences between SB and DB estimates in the second valuation scenario for treatments 2 and $3 .^{9}$

Finally, the treatment effect is also sizeable and statistically significant for the second valuation scenario (See Table 3). Consequently, there is a combined effect of information and repetitive learning in attenuating the inconsistency in these responses.

\section{The results of advanced information and repetitive learning on statistical efficiency}

Both advanced information and repeated valuation scenarios seem to result in increased statistical efficiency. From Table 1 we see that the standard errors decreases in Treatments 2 and 3, and that they also decrease for the second good valued. However, it is somewhat misleading to look at the standard errors alone since the mean estimates change as well. In order to illustrate this 
more clearly we calculate the coefficient of variation for each estimated WTP; i.e. the ratio of the standard deviation to the mean. Results can easily be derived from Table 1. Interestingly, the coefficient of variation is only reduced by advanced information in the SB estimates for the first valuation scenario where the coefficient of variation decreases from 0.19 in the treatment with uninformed respondents to 0.13 and 0.10 in treatments 2 and 3 respectively. This suggests that advanced information, perhaps surprisingly, only affects the efficiency of the SB estimates and it has no effect on the efficiency of the DB estimates.

\section{The results on bid dependent anchoring tests and preference formation theories}

In this section we report the findings from our anchoring models to investigate the effects of advanced information and repetitive learning on anchoring and the apparent processes of preference formation. These tests allows us to determine whether the internal consistency between SB and DB estimates is consistent with the standard theory of pre-existing well-formed preferences, the discovered preference theory of Plott 1996 and Plott and Zeiler 2005 or with coherent arbitrariness by anchoring their WTP on the first bid level in the double referendum. The estimated anchoring models are shown in Appendix A Table A2. Table 4 shows the values of the anchoring coefficients for each of our 6 treatments.

> $\quad$ Table 4

The estimated anchoring coefficients reveal a number of interesting results. First, the increased levels of advance information provided to the respondent significantly reduce the value of the 
anchoring parameter from 0.83 to 0.37 for the first good valued (Hydroelectric power). However, in all three cases, the anchoring coefficient is statistically significant, indicating that respondents are anchoring on the first bid level to some extent in all three first good treatments. Second, for the second good valued (Thermo-electric power baseline), the anchoring parameters are reduced in the two informed treatments and are not significantly different from zero. Thus, with repetitive learning and advanced information we find no support for an influence of anchoring.

Following an insightful suggestion from an anonymous referee, we re-estimated the double bounded models for the three treatments and the two goods using a Bivariate Probit approach. Following methods outlined in Hanneman and Kanninen 1999 we add constraints to the estimated parameters ensuring a single WTP for the first and second bids with an unconstrained rho statistic. This Bivariate Probit model produced double bound estimates of WTP for the first good valued in the Control (No Advanced Information) Treatment which were consistent with the SBDC estimates for the same good and treatment, (albeit with a rho value equal to 0.67) - See Appendix B, Table B1. However, the underlying DBDC preference data for this initial valuation control treatment clearly fails the McFadden 1994 Consistency Test - See Appendix B, Table B3. By contrast, the advanced information and repetitive learning effects explored in this paper can produce a high degree of preference consistency in DBDC data, as shown in Appendix B, Table B4; this response data can clearly pass the McFadden 1994 Consistency Test and also provides consistent SBDC and DBDC estimates of WTP in Table B2. 


\section{DISCUSSION AND CONCLUSIONS ON LEARNING AND PREFERENCE FORMATION THEORIES}

This paper studies the effect of advanced information learning and repetitive learning on the reduction of inconsistencies between single and double bounded welfare estimates and bid dependent anchoring effects in DBDC contingent valuation datasets. We show that the inclusion of these processes of learning, especially when combined, significantly reduces both anomalies, producing internally consistent and non-bid dependent WTP estimates. Furthermore, the advanced information estimates also present significantly lower standard errors showing better statistical efficiency than for the first good uninformed DBDC valuations as currently used in most published DBDC studies. In Table 5 we summarize the results for each of the six different DBDC methods used in this paper. Of particular interest are the four new methods that introduce advanced information on the institutions, the goods to be valued and IC double referendum decision rules. These LDCV designs perform much better in tests for DBDC convergence, statistical efficiency and anchoring than the traditional method in Hanneman et al. 1991 or the repetition only method of LDCV in Bateman et al. 2008.

〉> Table 5

The greatest degree of SB-DB consistency, statistical efficiency and non-significant anchoring effects occur by combining the advanced information treatments with repetitive learning, by valuing a second good. As in Bateman et al. 2008 internal consistency is easier to achieve than freedom from bid dependent anchoring in DBDC data sets. Advanced information learning in both treatments is capable of producing SB-DB consistency in WTP estimates without repetition. The 
unexpected apparent consistency in the uninformed treatment is related to the very large variance on the SB estimate, which was also observed by Bateman et al. 2008. Such SB variance cannot only be addressed by repetitive mechanisms following Hanneman et al. 1991 but by the advanced information treatments introduced in this study.

Bid dependent anchoring is however more difficult to address through learning. While advanced information results in substantial reductions in the anchoring parameters, these parameters only become nonsignificant when advanced information is combined with repetitive learning in valuing a second good. In the case of our uninformed second valuation, neither consistency nor nonarbitrariness is demonstrated although statistical efficiency is improved and anchoring effects lessened from the uninformed first valuation.

The evidence in Table 5 with respect to the major theories of preference formation is clear. If apriori well-formed preferences existed in any of our datasets they would be exhibited by consistency and lack of bid dependent anchoring in the first valuation treatments. While there is evidence of consistency in the informed first valuation treatments, anchoring is always present. As a result this theory of a-priori well-formed preference can be largely discounted for initial valuation DBDC. Many other field studies have similarly found an absence of initial well-formed preferences with evidence abounding of anchoring and large value differences in SB and DB WTP estimates; see Carson and Groves 2007, 2010. Similarly the newer repetitive formats of Discrete Choice Experiments are starting to produce abundant evidence that the first choice in the sequence "is the hardest" (Carlsson et al. 2012; Hess et al. 2012) and that initial choices show preference inconsistency when compared to subsequent choices and larger variance that all subsequent choices (Czajkowski et al. 2014; Day et al. 2014 Campbell et al. 2015). 
Our findings show clear evidence of Coherent Arbitrariness with considerable consistency in SB-DB WTP values in our two informed first valuation treatments where in spite of reductions in the anchoring parameter estimate, bid dependency remain statistically significant in these informed initial valuation treatments. Contrary to other studies, our second uninformed valuation shows a significant difference between SB and DB WTP. Also exhibiting a significant bid dependent anchoring parameter this particular method shows both types of bias and must be classified as showing both inconsistent and arbitrary preferences. By contrast the two informed repetitive valuations convincingly show consistent WTP and non-anchored preferences and are therefore strongly consistent with Plott's Discovered Preference Hypothesis showing well-formed preferences when both informed and repetitive learning processes are combined within the LDCV design. Previous studies on repetitive learning have also tended to endorse the Discovered Preference Hypothesis. This paper strongly replicates these findings of Bateman et al. 2008 in an enhanced design, field application, while also providing for the first time convincing evidence for Coherent Arbitrary Preferences when different levels of advanced information are provided in nonrepetitive one-off DBDC studies.

The policies implications of our findings are clear. The DBDC format can produce inconsistent and/or bid dependent estimates all equating to irrational preferences. When the DBDC is used for policy purposes; e.g. this study on renewable energy in Chile, the Herriges and Shogren 1996 bid dependency test and the SBDB consistency test outlined in Equation 2 should be presented. This would assure policy makers that preferences and values are free from internal inconsistency and the Tufano 2010 and Ariely et al. 2003 arbitrariness finding. Understanding of these effects in DCEs lags behind DBDC. Here the unresolved preference inconsistency of learning and fatigue 
remains a subject of recent major papers such as Hess et al. 2012; Carlsson et al. 2012; and Campbell et al. 2015 while the arbitrariness of preferences is an interesting area open for further research. The importance of Stated Preference Methods demonstrating rational preference elicitation cannot be over-emphasised given the importance of natural resource decisions that these studies have input to. This is witnessed by the 2012 symposium on Contingent Valuation in The Journal of Economic Perspectives Vol 26 Issue 4: "From Exxon to BP: Has Some Number Become Better than no Number?" (Kling et al. 2012). 


\section{Appendix A: Model Estimations}

Table A1.

SB and DB Logit models for Treatments 1 to 3 and valuations 1 and 2. $\mathrm{t}$ values in parentheses.

\begin{tabular}{|c|c|c|c|c|c|c|}
\hline \multicolumn{7}{|c|}{$\mathbf{1}^{\text {st }}$ Valuation (Hydropower baseline) } \\
\hline & \multicolumn{2}{|c|}{$\begin{array}{l}\text { Treatment 1: } \\
\text { Uninformed }\end{array}$} & \multicolumn{2}{|c|}{$\begin{array}{c}\text { Treatment 2: } \\
\text { Informed DBDC }\end{array}$} & \multicolumn{2}{|c|}{$\begin{array}{c}\text { Treatment 3: } \\
\text { Informed DBDC +ICDR }\end{array}$} \\
\hline \multirow{3}{*}{ Constant } & SB & DB & SB & DB & SB & DB \\
\hline & 2.37 & 2.35 & 2.52 & 2.36 & 2.47 & 2.34 \\
\hline & $(7.39)$ & $(11.94)$ & $(8.00)$ & $(11.15)$ & $(8.30)$ & (11.54) \\
\hline \multirow{2}{*}{ Bid } & -0.50 & -0.61 & -0.67 & -0.71 & -0.72 & -0.70 \\
\hline & $(-3.33)$ & $(-12.12)$ & $(-4.49)$ & $(-12.44)$ & $(-5.16)$ & $(-13.08)$ \\
\hline $\begin{array}{c}\text { Log } \\
\text { Likelihood }\end{array}$ & -157.23 & -376.77 & -151.52 & -369.34 & -167.63 & -375.68 \\
\hline $\begin{array}{l}\text { Number of } \\
\text { Observations }\end{array}$ & 340 & 340 & 323 & 323 & 340 & 340 \\
\hline \multicolumn{7}{|c|}{$2^{\text {nd }}$ Valuation (Thermoelectric Baseline) } \\
\hline & \multicolumn{2}{|c|}{$\begin{array}{l}\text { Treatment 1: } \\
\text { Uninformed }\end{array}$} & \multicolumn{2}{|c|}{$\begin{array}{c}\text { Treatment 2: } \\
\text { Informed DBDC }\end{array}$} & \multicolumn{2}{|c|}{$\begin{array}{c}\text { Treatment 3: } \\
\text { Informed DBDC+ICDR }\end{array}$} \\
\hline \multirow{3}{*}{ Constant } & SB & DB & SB & DB & SB & DB \\
\hline & 2.16 & 2.31 & 1.92 & 1.79 & 1.88 & 1.96 \\
\hline & $(8.48)$ & $(14.00)$ & $(7.69)$ & $(11.61)$ & $(7.71)$ & $(12.88)$ \\
\hline \multirow{2}{*}{ Bid } & -0.42 & -0.49 & -0.50 & -0.49 & -0.43 & -0.45 \\
\hline & $(-6.33)$ & $(-14.23)$ & $(-7.46)$ & $(-13.12)$ & $(-6.83)$ & $(-13.67)$ \\
\hline $\begin{array}{c}\text { Log } \\
\text { Likelihood }\end{array}$ & -186.93 & -410.52 & -187.45 & -423.03 & -200.68 & -439.29 \\
\hline $\begin{array}{c}\text { Number of } \\
\text { Observations }\end{array}$ & 340 & 340 & 323 & 323 & 340 & 340 \\
\hline
\end{tabular}


Table A2.

Logit models with anchoring for Treatments 1 to 3 and valuations 1 and 2. $\mathrm{t}$ values in parentheses.

\begin{tabular}{cccc}
\hline \multicolumn{2}{c}{$\mathbf{1}^{\text {st }}$ Valuation (Hydropower baseline) } \\
\hline $\begin{array}{c}\text { Treatment 1: } \\
\text { Uninformed }\end{array}$ & $\begin{array}{c}\text { Treatment 2: } \\
\text { Informed DBDC }\end{array}$ & $\begin{array}{c}\text { Treatment 3: } \\
\text { Informed DBDC +ICDR }\end{array}$ \\
\hline Constant & 1.601 & 1.729 & 1.997 \\
Bid & $(6.41)$ & $(6.92)$ & $(7.98)$ \\
Gamma & -0.125 & -0.277 & -0.48 \\
& $(-1.10)$ & $(-2.48)$ & $(-4.31)$ \\
& 0.832 & 0.669 & 0.366 \\
Log Likelihood & $(5.39)$ & $(4.90)$ & $(2.289)$ \\
\hline Observations & -367 & -362 & -374 \\
\hline \hline
\end{tabular}

$2^{\text {nd }}$ Valuation (Thermoelectric Baseline)

\begin{tabular}{cccc}
\hline & $\begin{array}{c}\text { Treatment 1: } \\
\text { Uninformed }\end{array}$ & $\begin{array}{c}\text { Treatment 2: } \\
\text { Informed DBDC }\end{array}$ & $\begin{array}{c}\text { Treatment 3: } \\
\text { Informed DBDC + ICDR }\end{array}$ \\
\hline \multirow{2}{*}{ Constant } & 1.79 & 1.703 & 1.728 \\
& $(7.96)$ & $(7.04)$ & $(7.28)$ \\
Bid & -0.315 & -0.465 & -0.377 \\
& $(-5.66)$ & $(-8.39)$ & $(-7.10)$ \\
Gamma & 0.436 & 0.068 & 0.194 \\
& $(4.17)$ & $(0.59)$ & $(1.64)$ \\
\hline Log Likelihood & -403 & -423 & -438 \\
Observations & 340 & 323 & 340 \\
\hline
\end{tabular}


Appendix B: Value Consistency between Estimation Methods and Consistency in DBDC Response Data before and after Learning.

Table B1.

WTP for first good by estimation method in Chilean Pesos.

\begin{tabular}{lccc}
\hline Treatment & SBDC & DBDC & $\begin{array}{c}\text { Constrained } \\
\text { Bivariate Probit } \\
\text { (rho value) }\end{array}$ \\
\hline Control & 4,777 & 3,878 & $4,654(0.67)$ \\
\hline $\begin{array}{l}\text { Informed } \\
\text { DBDC +DR }\end{array}$ & 3,425 & 3,350 & $4,037(0.66)$ \\
\hline \hline
\end{tabular}

Table B2.

WTP for second good by estimation method in Chilean Pesos.

\begin{tabular}{lccc}
\hline Treatment & SBDC & DBDC & $\begin{array}{c}\text { Constrained } \\
\text { Bivariate Probit } \\
\text { (rho value) }\end{array}$ \\
\hline Control & 5,122 & 4,674 & $5,318(0.62)$ \\
\hline $\begin{array}{l}\text { Informed } \\
\text { DBDC +DR }\end{array}$ & 4,383 & 4,359 & $5,222(0.59)$ \\
\hline \hline
\end{tabular}


Table B3.

YES-NO (YN) and NO-YES (NY) responses to reverse ordering of the same bids in DBDC data for First Good Valued with Control (No Advanced Information) Treatment. (Test for Independence of ordering of YN and NY responses in DBDC after McFadden 1994)

\begin{tabular}{|c|c|}
\hline YN & NY \\
$500: 1000$ & $1000: 500$ \\
$16.1 \%$ & $2.3 \%$ \\
\hline $\mathrm{YN}$ & $\mathrm{NY}$ \\
$1000: 2000$ & $2000: 1000$ \\
$18.6 \%$ & $8.1 \%$ \\
\hline $\mathrm{YN}$ & $\mathrm{NY}$ \\
$2000: 3000$ & $3000: 2000$ \\
$19.8 \%$ & $14.9 \%$ \\
\hline
\end{tabular}

Table B4.

YES-NO (YN) and NO-YES (NY) responses to reverse ordering of the same bids in DBDC data for Second Good Valued with Advanced Information Treatment.

(Test for Independence of ordering of YN and NY responses in DBDC after McFadden 1994)

\begin{tabular}{|c|c|}
\hline $\mathrm{YN}$ & $\mathrm{NY}$ \\
$1000: 2000$ & $2000: 1000$ \\
$18.2 \%$ & $19.7 \%$ \\
\hline $\mathrm{YN}$ & $\mathrm{NY}$ \\
$2000: 3000$ & $3000: 2000$ \\
$26.2 \%$ & $21.3 \%$ \\
\hline $\mathrm{YN}$ & $\mathrm{NY}$ \\
$3000: 6000$ & $6000: 3000$ \\
$26.7 \%$ & $26.3 \%$ \\
\hline
\end{tabular}




\section{Acknowledgements:}

The authors are grateful to the Gibson Institute at Queen's University Belfast and the Latin American Environmental Economics Program (LACEEP) for financial support.

\section{References}

Alberini, Anna. 1995. "Efficiency vs. bias of willingness-to-pay estimates: bivariate and intervaldata models". Journal of Environmental Economics and Management 29 (2): 169-180.

Ariely, Dan, George Loewenstein and Drazen Prelec 2003 “Coherent arbitrariness”: stable demand curves without stable preferences". The Quarterly Journal of Economics 118 (1): 73-105.

Ariely, Dan, George Loewenstein and Drazen Prelec. 2006. Tom Sawyer and the construction of value. Journal of Economic Behavior and Organization, 60 (1): 1-10.

Arrow, Kenneth, Robert Solow, Paul R. Portney, Edward E. Leamer, Roy Radner, and Howard Schuman. 1993. Report of the NOAA panel on contingent valuation. Federal register 58, no. 10 (1993): 4601-4614.

Bateman, Ian J., Diane Burgess, W. George Hutchinson, David I. Matthews. 2008. "Learning design contingent valuation (LDCV): NOAA guidelines, preference learning and coherent arbitrariness". Journal of Environmental Economics and Management 55 (2): 127-141.

Bateman, Ian J., Matthew Cole, Philip Cooper, Stavros Georgiou, David Hadley and Gregory L. Poe. 2004. "On visible choice sets and scope sensitivity". Journal of Environmental Economics and Management 47 (1): 71-93. 
Bradley, Mark and Andrew Daly. 1994. "Use of the logit scaling approach to test for rank-order and fatigue effects in stated preference data”. Transportation 21 (2): 167-184.

Braga, Jacinto and Chris Starmer. 2005. "Preference anomalies, preference elicitation and the discovered preference hypothesis". Environmental and Resource Economics 32 (1): 55-89.

Brazell, Jeff, and Jordan Louviere. 1996. "Helping, learning, and fatigue: An empirical investigation of length effects in conjoint choice studies". Working Paper. Department of Marketing, The University of Sydney.

Burton, Anthony C., Katherine S. Carson, Susan M. Chilton and W. George Hutchinson 2003. “An experimental investigation of explanations for inconsistencies in responses to second offers in double referenda". Journal of Environmental Economics and Management 46 (3): 472-489.

Burton, Anthony C., Katherine S. Carson, Susan M. Chilton and W. George Hutchinson. 2009. "Why do people Non-Demand Revel in Hypothetical Double Referenda for Public Goods". Applied Economics, 41 (27): 3561-3569.

Carlsson, F., Morkbak, M., Olsen, S. 2012. "The first time is the hardest: A test of ordering effects in choice experiments". Journal of Choice Modelling 5 (2): 19-37

Cameron, Trudy Ann and Quiggin, John. 1994. "Estimation using contingent valuation data from a "dichotomous choice with follow-up" questionnaire". Journal of Environmental Economics and Management 27 (3): 218-234.

Campbell, Danny, Marco Boeri, Edel Doherty and W. George Hutchinson. 2015. "Learning, fatigue and preference formation in discrete choice experiments". Journal of Economic Behavior and Organization 119: 345-363. 
Carson, Katherine Silz, Susan M. Chilton, and W. George Hutchinson. 2009. "Necessary conditions for demand revelation in double referenda". Journal of Environmental Economics and Management 57 (2): 219-225.

Carson, Richard T., and Theodore Groves. 2007. "Incentive and informational properties of preference questions". Environmental and Resource Economics 37 (1): 181-210.

Carson, Richard T., and Theodore Groves. 2010. "Incentive and information properties of preference questions". University of California at San Diego, Economics Working Paper Series.

Carson, Richard T., Robert C. Mitchell, Michael Hanemann, Raymond J. Kopp, Stanley Presser, and Paul A. Ruud. 2003. "Contingent valuation and lost passive use: damages from the Exxon Valdez oil spill”. Environmental and Resource Economics 25 (3): 257-286.

Cooper, Joseph C. 1994. "A Comparison of Approaches to Calculating Confidence Intervals for Benefit Measures from Dichotomous Choice Contingent Valuation Surveys". Land Economics 70 (1): 111-122.

Cooper, Joseph C., Michael Hanemann, and Giovanni Signorello. 2002. “One-and-one-half-bound dichotomous choice contingent valuation". Review of Economics and Statistics 84 (4): 742-750.

Cummings, Ronald G., Steven Elliott, Glenn W. Harrison, and James Murphy. 1997. “Are hypothetical referenda incentive compatible?" Journal of Political Economy 105 (3): 609-621.

Cummings, Ronald G., and Laura O. Taylor. 1999. "Unbiased value estimates for environmental goods: A cheap talk design for the contingent valuation method". The American Economic Review 89 (3): 649-665.

Czajkowski, Mikolaj, Marek Giergiczny, and William H. Greene 2014. "Learning and fatigue effects revisited: Investigating the effects of accounting for unobservable preference and scale heterogeneity". Land Economics 90 (2): 324-351. 
Day, Brett, Ian J. Bateman, Richard T. Carson, Diane Dupont, Jordan J. Louviere, Sanae Morimoto, Riccardo Scarpa, and Paul Wang. 2012. "Ordering effects and choice set awareness in repeatresponse stated preference studies". Journal of Environmental Economics and Management 63(1): 73-91.

DeShazo, Jay R. 2002. "Designing transactions without framing effects in iterative question formats". Journal of Environmental Economics and Management 43 (3): 360-385.

Efron, B., Tibshirani, R.J. 1993. An introduction to the bootstrap, Chapman \& Hall/CRC press, London.

Gibbard, Allan. 1973. "Manipulation of voting schemes: a general result". Econometrica 41 (4): $587-601$.

Giraud, Kelly L., John B. Loomis, and Joseph C. Cooper. 2001. “A Comparison of Willingness to Pay Estimation Techniques from Referendum Questions: Application to Endangered Fish". Environmental and Resource Economics 20 (4): 331-346.

Hanemann, W. Michael. 1984. "Welfare evaluations in contingent valuation experiments with discrete responses". American Journal of Agricultural Economics 66 (3): 332-341.

Hanemann, Michael, and Barbara Kanninen 1999. The Statistical Analysis of Discrete-Response CV Data. Chp 11, pp 302-441 in Bateman I.J., 1999 and Willis K.G. Valuing Environmental Preferences, Oxford University Press

Hanemann, Michael, John Loomis, and Barbara Kanninen. 1991. "Statistical efficiency of doublebounded dichotomous choice contingent valuation". American Journal of Agricultural Economics 73 (4): 1255-1263. 
Herriges, Joseph A., and Jason F. Shogren. 1996. "Starting point bias in dichotomous choice valuation with follow-up questioning". Journal of Environmental Economics and Management 30 (1): 112-131.

Hess, Stephane, David A. Hensher, and Andrew Daly. 2012. "Not bored yet- revisiting fatigue in stated choice experiments”. Transportation Research Part A. 46 (3): 626-644.

Hutchinson, W. George, Riccardo Scarpa, Susan M. Chilton, and T. McCallion. 2001. "Parametric and nonparametric estimates of willingness to pay for forest recreation in Northern Ireland: a discrete choice contingent valuation study with follow-ups". Journal of Agricultural Economics 52 (1): 104-122.

Kling, Catherine L. 1991. "Estimating the Precision of Welfare Measures". Journal of Environmental Economics and Management 21 (3): 244-259.

Kling, Catherine L., Daniel J. Phaneuf, and Jinhua Zhao. 2012. "From Exxon to BP: Has Some Number Become Better Than No Number?" Journal of Economic Perspectives 26(4): 3-26.

List, John A. 2002. "Preference reversals of a different kind: The more is less phenomenon". American Economic Review 92 (5): 1636-1643.

List, John A. 2003. "Does Market Experience Eliminate Market Anomalies?” Quarterly Journal of Economics 118 (1): 41-71.

List, John A. 2004. "Neoclassical theory versus prospect theory: Evidence from the marketplace". Econometrica 72 (2), 615-625.

Loomes, Graham, Chris Starmer, and Robert Sugden. 2003. "Do anomalies disappear in repeated markets?” The Economic Journal 113 (486): 153-166. 
Loomis, John, Thomas Brown, Beatrice Lucero, and George Peterson. 1997. "Evaluating the validity of the dichotomous choice question format in contingent valuation". Environmental and Resource Economics 10 (2): 109-123.

Louviere, Jordan J., David A. Hensher, and Joffre D. Swait. 2000. Stated Choice Methods: Analysis and Applications. Cambridge University Press.

Maniadis, Zacharias, Fabio Tufano, and John A. List. 2014. “One swallow doesn’t make a summer: New evidence on anchoring effects”. American Economic Review 104 (1): 277-290.

McFadden, Daniel, 1994. "Contingent valuation and social choice". American Journal of Agricultural Economics 76 (4): 689-708.

NEC Report on electricity prices. April 2007. Available atwww.cne.cland Statistics of CDEC and Centro de Despacho Económico de Carga (Economic Center of Charge Service). Available at:http://www.cdec-sic.cl/

Plott, Charles R. 1996. "Rational individual behavior in markets and social choice processes: the discovered preference hypothesis", in: Rational Foundations of Economic Behavior, Arrow, K., Colombatto, E., Perleman, M. and Schmidt, C. (Eds.), Macmillan, London, St. Martin's, New York, pp. 225-250.

Plott, Charles R. and Kathryn Zeiler. 2005. "The willingness to pay-willingness to accept gap, the "endowment effect", subject misconceptions, and experimental procedures for eliciting valuations". The American Economic Review 95 (3): 530-545.

Satterthwaite, Mark Allen. 1975. "Strategy-proofness and Arrow's conditions: existence and correspondence theorems of voting procedures and social welfare functions". Journal of Economic Theory 10 (2): 187-217. 
Scarpa, Riccardo and Ian Bateman. 2000. "Efficiency gains afforded by improved bid design versus follow up valuation questions in discrete choice CV studies". Land Economics 76 (2): 299-311. Taylor, Laura O., Michael McKee, Susan K. Laury, and Ronald G. Cummings. 2001. "Induced value tests of the referendum voting mechanism”. Economics Letters 71 (1): 61-66.

Tufano, Fabio. 2010. "Are "true" preferences revealed in repeated markets? An experimental demonstration of context-dependent valuations". Experimental Economics 13 (1): 1-13. 
Figure 1.

Repetitive Learning Design with Three Information Treatments and Test Statistics for SB DB Consistency and Anchoring Effects

\begin{tabular}{|c|c|c|}
\hline Treatment & $\begin{array}{l}\frac{1^{\text {st }} \text { Valuation }}{\text { Renewable energy instead of }} \\
\text { Hydro power }\end{array}$ & $\begin{array}{l}\quad \frac{2^{\text {nd }} \text { Valuation }}{\text { Renewable energy instead }} \\
\text { of Thermoelectric power }\end{array}$ \\
\hline 1. Uninformed & $\Delta \overline{W T P}_{1}^{1} \quad \gamma_{1}^{1}$ & $\Delta \overline{W T P}_{1}^{2} \quad \gamma_{1}^{2}$ \\
\hline 2. Informed of DBDC process & $\Delta \overline{W T P}_{2}^{1} \quad \gamma_{2}^{1}$ & $\Delta \overline{W T P}_{2}^{2} \quad \gamma_{2}^{2}$ \\
\hline $\begin{array}{l}\text { 3. Informed of DBDC process and } \\
\text { Incentive Compatible Double } \\
\text { Referendum Decision Rules }\end{array}$ & $\Delta \overline{W T P}_{3}^{1} \quad \gamma_{3}^{1}$ & $\Delta \overline{W T P}_{3}^{2}$ \\
\hline
\end{tabular}

$\Delta \overline{W T P}_{k}^{i}=$ Difference between SB and DB for the advanced information treatment $k$ and the valuation $i$. $\gamma_{k}^{i}=$ Anchoring parameter for the advanced information treatment $k$ and the valuation $i$. 
Table 1.

SB and DB mean WTP first and second valuations for Treatments $k=1$ to 3 .

Standard errors calculated using the Delta Method in parentheses.

\begin{tabular}{|c|c|c|c|c|c|c|}
\hline \multirow[b]{2}{*}{ Treatment } & \multicolumn{3}{|c|}{$\begin{array}{c}\text { 1st Valuation } \\
\text { Hydroelectric power }\end{array}$} & \multicolumn{3}{|c|}{$\begin{array}{l}\text { 2nd Valuation } \\
\text { Thermoelectric power }\end{array}$} \\
\hline & $\overline{W T P}_{S B, k}^{1}$ & $\overline{W T P}_{D B, k}^{1}$ & $\Delta \overline{W T P}_{k}^{1}$ & $\overline{W T P}_{S B, k}^{2}$ & $\overline{W T P}_{D B, k}^{2}$ & $\Delta \overline{W T P}_{k}^{2}$ \\
\hline 1) Uninformed & $\begin{array}{l}4,777 \\
(902)\end{array}$ & $\begin{array}{l}3,878 \\
(191)\end{array}$ & 898 & $\begin{array}{l}5,122 \\
(414)\end{array}$ & $\begin{array}{l}4,674 \\
(230)\end{array}$ & 447 \\
\hline Coeff. Variation & 0.19 & 0.05 & & 0.08 & 0.05 & \\
\hline 2) Informed DBDC & $\begin{array}{l}3,787 \\
(474)\end{array}$ & $\begin{array}{l}3,344 \\
(161)\end{array}$ & 444 & $\begin{array}{l}3,850 \\
(265)\end{array}$ & $\begin{array}{l}3,632 \\
(218)\end{array}$ & 218 \\
\hline Coeff. Variation & 0.13 & 0.05 & & 0.07 & 0.06 & \\
\hline $\begin{array}{l}\text { 3) Informed DBDC + } \\
\text { ICDR }\end{array}$ & $\begin{array}{l}3,425 \\
(351)\end{array}$ & $\begin{array}{l}3,350 \\
(161)\end{array}$ & 75 & $\begin{array}{l}4,383 \\
(318)\end{array}$ & $\begin{array}{l}4,359 \\
(244)\end{array}$ & 24 \\
\hline Coeff. Variation & 0.10 & 0.05 & & 0.07 & 0.06 & \\
\hline
\end{tabular}

Note: 1 USD $=470$ Chilean Pesos (CLP) at the time of the survey. 
Table 2.

Consistency tests of difference in mean WTP, Ho: $\Delta \overline{W T P}_{k}^{i}=0$ for both goods (valuations $i=1$ and $i=2)$.

\begin{tabular}{lcccc}
\hline \multicolumn{1}{c}{ Treatment } & \multicolumn{2}{c}{$\begin{array}{c}\text { 90\% Confidence } \\
\text { Interval }\end{array}$} & $\begin{array}{c}\text { Test Result } \\
\mathbf{H}_{\mathbf{0}}: \Delta \overline{W T P}_{k}^{i}=0\end{array}$ \\
\hline Treatment 1: Uninformed & $\Delta \overline{W T P}_{1}^{i}$ & $b_{0.05}$ & $b_{0.95}$ & \\
\hline First valuation & 1445 & -36 & 3886 & Accept \\
Second valuation & 514 & 28 & 1149 & Reject \\
\hline Treatment 2: Informed DBDC & $\Delta \overline{W T P}_{2}^{i}$ & $b_{0.05}$ & $b_{0.95}$ & \\
\hline First valuation & 500 & -92 & 1417 & Accept \\
Second valuation & 234 & -19 & 499 & Accept \\
\hline Treatment 3: Inform DBDC +ICDR & $\Delta \overline{W T P}_{3}^{i}$ & $b_{0.05}$ & & \\
\hline First valuation & 148 & -321 & 783 & Accept \\
Second valuation & 42 & -258 & 377 & Accept \\
& & & & \\
\hline
\end{tabular}


Table 3.

Tests of Treatment differences $\Delta \overline{W T P}_{k}^{i}-\Delta \overline{W T P}_{k+1}^{i}>0$

\begin{tabular}{|c|c|c|c|}
\hline & $\Delta \overline{W T P}_{k}^{i}-\Delta \overline{W T P}_{k+1}^{i}$ & $\begin{array}{c}\text { t-test, } \\
\text { P-value } \mathbf{H}_{\mathbf{0}} \text { : } \\
\Delta \overline{W T P}_{k}^{i}-\Delta \overline{W T P}_{k+1}^{i}>0\end{array}$ & Test result \\
\hline \multicolumn{4}{|l|}{ Treatment 1 vs 2} \\
\hline \multicolumn{4}{|l|}{ First valuation } \\
\hline$\Delta \overline{W T P}_{1}^{1}-\Delta \overline{W T P}_{2}^{1}$ & 945 & 0.000 & Accept \\
\hline \multicolumn{4}{|l|}{ Second valuation } \\
\hline$\Delta \overline{W T P}_{1}^{2}-\Delta \overline{W T P}_{2}^{2}$ & 280 & 0.000 & Accept \\
\hline \multicolumn{4}{|l|}{ Treatment 2 vs 3} \\
\hline \multicolumn{4}{|l|}{ First valuation } \\
\hline$\Delta \overline{W T P}_{2}^{1}-\Delta \overline{W T P}_{3}^{1}$ & 353 & 0.000 & Accept \\
\hline \multicolumn{4}{|l|}{ Second valuation } \\
\hline$\Delta \overline{W T P}_{2}^{2}-\Delta \overline{W T P}_{3}^{2}$ & 192 & 0.000 & Accept \\
\hline
\end{tabular}




\section{Table 4.}

Estimated anchoring coefficients, $\gamma_{k}^{i}$, for each treatment and valuation scenario.

\begin{tabular}{lcccc}
\hline Treatment & \multicolumn{2}{c}{$\begin{array}{c}\text { 1st Valuation } \\
\text { Hydroelectric power }\end{array}$} & \multicolumn{2}{c}{$\begin{array}{c}\text { 2nd Valuation } \\
\text { Thermoelectric power }\end{array}$} \\
\hline & $\gamma_{k}^{i}$ & $\begin{array}{c}\text { Standard } \\
\text { Errors }\end{array}$ & $\gamma_{k}^{i}$ & $\begin{array}{c}\text { Standard } \\
\text { Errors }\end{array}$ \\
\hline 1. Uninformed & 0.83 & $(0.15)$ & 0.44 & $(0.10)$ \\
\hline 2. Informed DBDC & 0.67 & $(0.14)$ & 0.07 & $(0.12)$ \\
\hline 3: Informed DBDC +ICDR & 0.37 & $(0.16)$ & 0.19 & $(0.12)$ \\
\hline
\end{tabular}


Table 5.

Summary of results for first and repeat valuations for the three DBDC treatments

\begin{tabular}{cccc}
\hline DBDC Methods & $\begin{array}{c}\text { Consistency in } \\
\text { DBDC data } \\
\Delta \overline{W T P}=0\end{array}$ & $\begin{array}{c}\text { No Anchoring in } \\
\text { DBDC data, } \gamma_{k}^{i}=0\end{array}$ & $\begin{array}{c}\text { Preference } \\
\text { formation theory } \\
\text { implied }\end{array}$ \\
\hline $\begin{array}{c}\text { First valuation } \\
\text { Uninformed }\end{array}$ & Yes & No & $\begin{array}{c}\text { Coherent } \\
\text { Arbitrariness }\end{array}$ \\
\hline $\begin{array}{c}\text { First valuation } \\
\text { Informed of DBDC }\end{array}$ & Yes & No & $\begin{array}{c}\text { Coherent } \\
\text { Arbitrariness }\end{array}$ \\
\hline $\begin{array}{c}\text { First valuation } \\
\text { Informed of DBDC } \\
\text { and ICDR }\end{array}$ & Yes & No & $\begin{array}{c}\text { Coherent } \\
\text { Arbitrariness }\end{array}$ \\
\hline $\begin{array}{c}\text { Second Valuation } \\
\text { Uninformed }\end{array}$ & No & No & Non Coherent and \\
Arbitrary
\end{tabular}




\section{Footnotes}

[1] For a detailed review of the method see Hanemann 1984; Bateman et al. 2002.

[2] The earlier literature on the SB-DB inconsistency in first good valuations was based on behavioural explanations of this inconsistency and how inconsistency in voting patterns between SB and DB referenda could arise. Such theories are well reviewed in Carson and Groves 2007; they include "surprise" at the appearance of the second vote, "averaging" the first and second bid values, and gain-loss asymmetries. An experiment testing several of these theories is reported in Burton et al. 2003; while Burton et al. 2009 studies the voting patterns arising in the initial double referendum from competing theories. It would appear that different individual voters are motivated by different strategies and patterns of response to the initial double referendum including demand revealing responses. This makes modelling such response problematic.

[3] Maniadis et al. 2014 question the robustness of the type of initial value anchoring effect found in studies such as Ariely et al. 2003 and they call for independent replications to confirm such findings. The Shaping Hypothesis of Tufano 2010 and Loomes et al. 2003 is based on the dependency of an immediately preceding valuation. This has similarities to the Herriges and Shogren 1996 bid dependency model, showing the effect of an initial SB bid level on the response to the follow up DB bid. This type of "anchoring" within SBDB valuation appears to be a very robust effect frequently replicated in many Stated Preferences data sets of this type. This is the type of shaping or bid dependency explored in our paper.

[4] Please note $\Delta \overline{W T P}_{k}^{i}$ is used throughout this paper as the difference in the WTP for the same good elicited from the same dataset using the SBDC and the DBDC elicitation methods. This is an important and well documented test of internal inconsistency in the DBDC method; see Carson and Groves 2007, 2010.

[5] The wording used in this part of the questionnaire was: "In producing the 15\% extra electricity required in Chile we are looking at how much more you would be willing to pay for this renewables alternative over the two other types of energy. In what follows you will be asked how you would vote if a referendum was held to choose between renewable energy and each of the other alternatives in this order: First, renewable energy versus hydropower and second renewable energy versus thermoelectric power". 
[6] 1 USD=470 Chilean Pesos (CLP) at the time of the survey.

[7] These two status quo alternatives are the two real options that Chile has available for increasing energy generation in order to meet the rising energy demand of the country.

[8] Variance of the differences, $\operatorname{var} \Delta \mathrm{WTP}=\operatorname{var}(\mathrm{WTPSB}-\mathrm{WTPDB})=\operatorname{var}(\mathrm{WTPSB})+$ $\operatorname{var}(\mathrm{WTPDB})-2 * \operatorname{cov}(\mathrm{WTPSB}-\mathrm{WTPDB})$. In non-independent samples, the covariance is not zero, therefore the use of a statistical test designed for independent samples is not appropriate.

[9] Although we should be careful with directly comparing the estimates between the valuation scenarios since they involve different goods, we see that the difference between SB and DB mean WTP is consistently lower in the second valuation scenario for all treatments. Thus, there is an effect of repetitive learning on consistency even for the treatments where respondents already obtain the information about the institution, the goods valued and IC double referendum decision rules in advance. 